\title{
PD98059-inhibited invasion of Dunning rat prostate cancer cells involves suppression of motility but not MMP-2 or uPA secretion
}

\author{
TUANGPORN SUTHIPHONGCHAI, SUCHADA PHIMSEN, USAWADEE SAKULKHU and RUTAIWAN TOHTONG
}

\author{
Department of Biochemistry, Faculty of Science, Mahidol University, Rama 6 Road, Bangkok 10400, Thailand
}

Received December 13, 2005; Accepted February 6, 2006

\begin{abstract}
Up-regulation of extracellular-regulated kinases 1/2 (ERK1/2) has been implicated in tumor progression and metastasis in many types of cancer. We have previously shown that ERK1/2 is necessary for invasiveness of Dunning rat prostatic adenocarcinoma cell lines in which levels of activated ERK1/2 correlate with the metastatic potential. Here, we further examined the biological effects of elevated ERK1/2 in the highly metastatic Dunning cell line, MLL, in which the abilities to invade and metastasize are enhanced relative to its progenitor strain. Inhibition of ERK1/2 activation by the MEK1 inhibitor, PD98059, dose-dependently reduced MLL cell invasiveness and motility with similar $\mathrm{IC}_{50}$ values. On the other hand, the abilities of MLL cells to adhere to the extracellular matrix, phosphorylate myosin regulatory light chain and secrete matrix-degrading enzymes, matrix metalloproteinase (MMP)-2 and urokinase plasminogen activator (uPA) were marginally, if at all, affected by PD98059 treatment. These data indicated that the inhibitory effect of PD98059 on the invasiveness of MLL cells was primarily due to the suppression of cell motility, and the up-regulation of ERK1/2 is, at least in part, responsible for the enhanced cellular motility and invasiveness of the MLL cells.
\end{abstract}

\section{Introduction}

Metastasis, the spreading of malignant cells from the primary site to form a tumor mass at distant organs of the body, is the major cause of death in cancer patients. One of the critical characteristics of a metastatic cell is invasion, the ability to penetrate and invade the extracellular matrix and surrounding tissue. Invasion is a multistep process, requiring the coordination of various events, including alteration of cell

Correspondence to: Dr Tuangporn Suthiphongchai, Department of Biochemistry, Mahidol University, Rama 6 Road, Bangkok 10400, Thailand

E-mail: sctsc@mahidol.ac.th

Key words: extracellular-regulated kinases, invasion, metastasis, matrix metalloproteinase-2, motility, PD98059, urokinase plasminogen activator adhesion, promotion of cell migration, and degradation of the extracellular matrix barrier (1). Specifically, metastatic cells adhere to the basement membrane, secrete matrix-degrading enzymes [viz. matrix metalloproteinases (MMPs) and urokinase plasminogen activator (uPA)] to degrade the extracellular matrix barrier, and migrate from its original site. Many of these processes are regulated by various signaling pathways, one of the best characterized being the Ras/MEK/ERK signaling pathway.

ERK1/2 is a mediator that can be activated by a phosphorylation cascade caused by a variety of growth factors, cytokines and adhesion molecules such as integrins. Upregulation of the MEK/ERK pathway has been found in many types of cancer, including breast, prostate, colon, and kidney cancer (2), and is correlated with tumor progression and metastasis $(3,4)$. Apart from proliferation, ERK1/2 has been associated with diverse biological processes involved in acquisition of the invasive phenotype, such as cell motility and extracellular matrix degradation. Inhibition of the ERK pathway by the MEK1 inhibitor, dominant negative MEK or antisense ERK inhibits cell migration in a variety of cell types, such as COS-7 (5) and MCF-7 cells (6). In addition, ERK1/2 is involved in the regulation of matrix-degrading enzymes, such as MMPs and UPA. A MEK inhibitor, U0126, suppresses uPA expression as well as MMP-9 and MMP-2 secretion in an ovarian cancer cell, OVCA 433 (7).

The Dunning sublines are a family of rat prostatic adenocarcinoma cell lines developed from the same parental origin, a Dunning tumor. Their invasion, migration, adhesion and matrix-degrading enzyme production correlate with their metastatic ability $(8,9)$. Previous studies from our laboratory on these cell lines showed that inhibition of ERK $1 / 2$ activation suppresses their invasive ability, and the level of activated ERK1/2 also correlates with their metastatic potential (10). Here, we further explored how ERK1/2 regulates the cell invasiveness of MLL, a highly metastatic Dunning cell line, and whether the enhancement of those metastatic factors results from an increase in ERK activation. The role of ERK1/2 in cell invasiveness was investigated by determining the effects of a MEK1 inhibitor, PD98059, on features critical for the invasiveness acquired by MLL cells. We show that PD98059 inhibited cell motility at a level similar to its inhibition of cell invasiveness, whereas its effects on adhesion and matrix-degrading enzymes were minimal, implying that PD98059 primarily inhibited cell invasion by suppressing cell motility. 


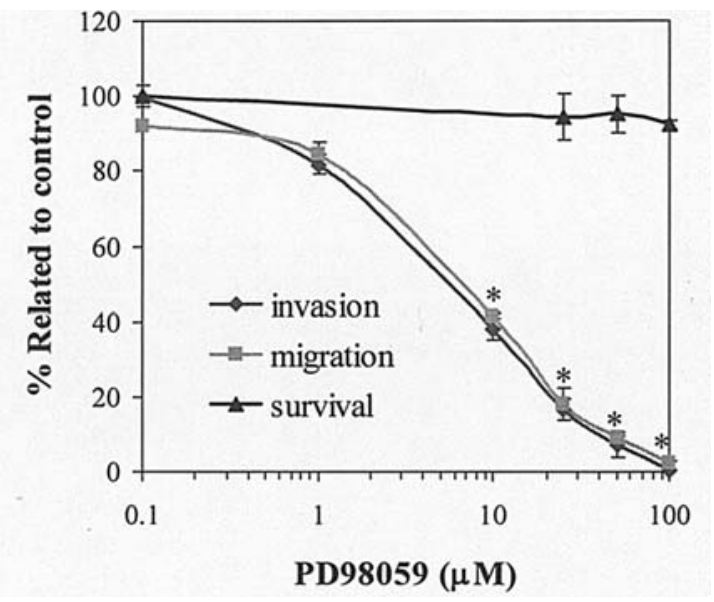

Figure 1. Effects of MEK1 inhibitor on in vitro invasion, motility and cell survival of MLL cells. MLL cells were resuspended in media containing indicated concentrations of PD98059 and plated on the upper compartment of a Matrigel-coated (for invasion assay) and non-coated (for motility assay) Transwell chamber. Cells treated with the same vehicle were used as the control. After 6-h incubation, the number of invaded cells was counted. In cell proliferation assay, cells were plated on a 96-well microplate for $48 \mathrm{~h}$, replenished with media containing PD98058, and incubated for $6 \mathrm{~h}$. The viable cells were analyzed by MTT assay, and OD was measured at $540 \mathrm{~nm}$. The results represent mean \pm SEM obtained from three separate experiments, each performed in duplicate. ${ }^{*}$ Significant difference of $\mathrm{P}<0.05$.

\section{Materials and methods}

Cell lines and culture condition. The highly metastatic Dunning rat prostatic adenocarcinoma cell line, MLL, was kindly provided by Dr Kenneth Pienta (University of Michigan, Ann Arbor, MI). In animal models, the MLL cells exhibited high metastatic ability to the lymph node and lung. (11). The cells were maintained in RPMI-1640 medium supplemented with $10 \%$ heat-inactivated fetal bovine serum (FBS), L-glutamine and $1 \mathrm{X}$ antibiotic-antimycotic liquid (Life Technologies Inc., Rockville, MD) at $37^{\circ} \mathrm{C}$ in a humidified atmosphere containing $5 \% \mathrm{CO}_{2}$.

In vitro invasion and migration assays. Cell invasiveness was determined using Transwell chambers (Corning Costar Corp., Cambridge, MA). Transwell inserts (8.0 $\mu \mathrm{m}$ pore) were coated with $100 \mu \mathrm{l}$ of $0.3 \mathrm{mg} / \mathrm{ml}$ of Matrigel (BectonDickinson, Bedford, MA) (12). Cell suspension ( $2 \times 10^{5}$ cells) in serum-free medium containing PD98059 (Cell Signaling Technology, Inc., MA) was added to the upper compartment of the Transwell chamber, and culture medium containing $10 \%$ FBS was added to the lower compartment. Control cells were treated with the same vehicle (dimethylsulfoxide, DMSO). After incubation for $6 \mathrm{~h}$ at $37^{\circ} \mathrm{C}$ in a humidified atmosphere containing $5 \% \mathrm{CO}_{2}$, non-invaded cells on the upper surface of the membrane filter were removed using a cotton swab. Cells that traversed the Matrigel and membrane layer were fixed and stained with $0.5 \%$ crystal violet. The number of invaded cells in five random microscopic fields (under 10x objective) was counted and expressed as the average number of invaded cells/field. Migration assays were also performed using Transwell chambers in a similar fashion to the invasion assay, but with no Matrigel coating on the upper Transwell compartment.

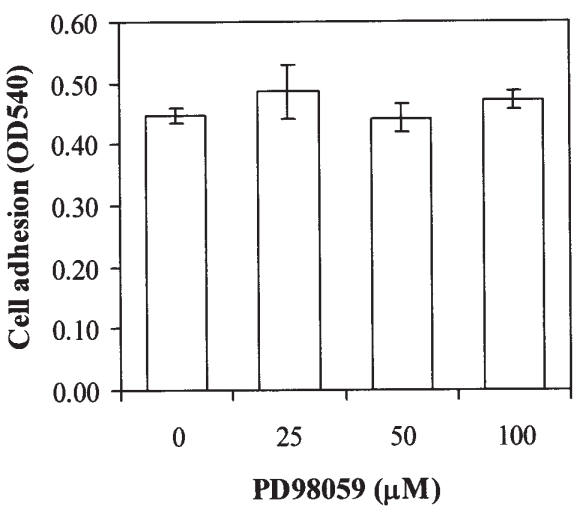

Figure 2. Effect of MEK1 inhibitor on adhesion of MLL cells to Matrigel. MLL cells were resuspended in media containing PD98059 and plated on a Matrigel-coated 96-well microplate. After 1-h incubation, the adherent cells were analyzed by MTT assay, and OD was measured at $540 \mathrm{~nm}$. The results represent mean \pm SEM obtained from three separate experiments, each performed in triplicate.

Cell survival assay. Cells $\left(1.5 \times 10^{3}\right)$ were plated onto 96-well plates for $48 \mathrm{~h}$ to allow attachment and then treated with medium containing PD98059 for $6 \mathrm{~h}$ in the same conditions as those of the invasion assay. After incubation, viable cells were analyzed by MTT assay (13). In brief, $50 \mu \mathrm{g}$ of MTT (USB Corp., Cleveland, OH) was added to the cell culture. After 3-h incubation, the solution was aspirated. MTT was converted into water-insoluble formazan in live cells and then dissolved by the addition of $200 \mu 1$ of DMSO. The absorbance was measured at $540 \mathrm{~nm}$.

Adhesion assay. Adhesion was determined as previously described (14). In brief, a 96-well plate was coated with $0.3 \mathrm{mg} / \mathrm{ml}$ of Matrigel followed by incubation with $3 \%$ BSA for $2 \mathrm{~h}$. Prior to the addition of cells, wells were washed twice with phosphate-buffered saline (PBS). Cells $\left(5 \times 10^{3}\right)$ in medium containing $10 \%$ FBS with various concentrations of PD98059 were added. After 1-h incubation at $37^{\circ} \mathrm{C}$, nonadhering cells were removed and the wells were gently washed twice with PBS. Living cells adhering to Matrigel were quantitated by MTT assay as described above.

The reported values of invasion, migration survival and adhesion assay are the means \pm SEM of results obtained from three independent experiments, each conducted in duplicate. Statistical significance, as determined using the t-test, was set at $\mathrm{P}$-value $<0.05$.

Gelatinase and plasminogen activator assay by zymography. Cells $\left(2 \times 10^{5}\right)$ were cultured in $60-\mathrm{mm}$ dish for $48 \mathrm{~h}$, washed twice and incubated in serum-free medium containing PD98059 for $6 \mathrm{~h}$, then conditioned medium and/or cells were harvested for zymogram analysis. Gelatinase activity of MMP-2 and MMP-9 secreted in the conditioned medium was analyzed in SDS-gelatin gel under non-reducing conditions as described previously (14). Briefly, $20 \%$ of total concentrated conditioned medium was mixed with non-reducing SDS sample buffer and electrophoresed in a 7.5\% SDS-PAGE containing $1 \mathrm{mg} / \mathrm{ml}$ of gelatin (Sigma-Aldrich Corp., St. Louis, MO). After electrophoresis, the gel was washed twice with $2.5 \%$ Triton X-100 and incubated in $50 \mathrm{mM}$ Tris- $\mathrm{HCl} \mathrm{pH} 7.5$ buffer containing $10 \mathrm{mM} \mathrm{CaCl}_{2}, 1 \mathrm{mM} \mathrm{ZnCl}{ }_{2}$ and $1 \%$ Triton X-100 
a

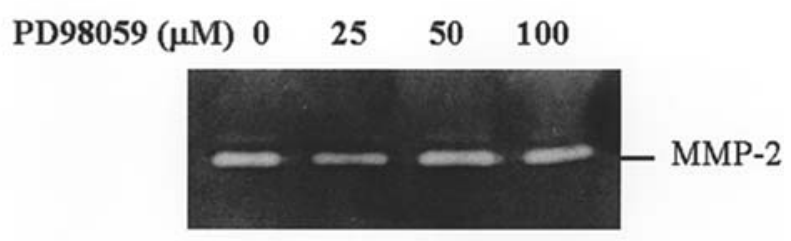

b

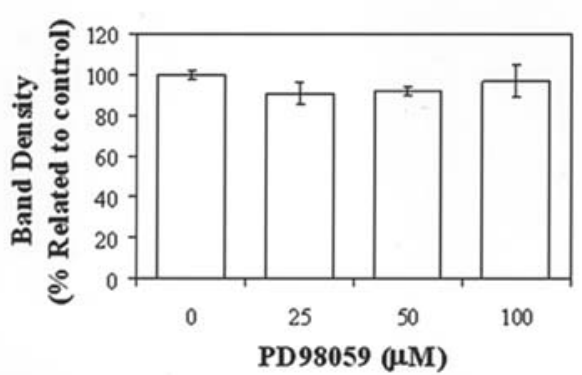

Figure 3. Gelatin zymography showing the effect of MEK1 inhibitor on the amount of MMP-2 secreted in conditioned medium of MLL cells. Cells were treated with PD98059 in serum-free media for $6 \mathrm{~h}$ and then $20 \%$ of the total concentrated conditioned medium was analyzed by gelatin zymography (a). The clear band at approximately $72 \mathrm{kDa}$ represents the gelatinase activity of MMP-2. The relative band densities (b) were quantitated using a gel densitometer, and the data represent the mean \pm SEM of band density as a percentage related to the control from three separate experiments

for $16-18 \mathrm{~h}$ at $37^{\circ} \mathrm{C}$, before staining with $0.5 \%$ Coomassie blue. After destaining, the gelatinolytic activity, appearing as a clear band on a blue background, was quantitated using a Bio-Rad GS700 gel scanner.

UPA activity in conditioned medium and bound uPA, eluted from cell surface by $50 \mathrm{mM}$ glycine $\mathrm{pH} 3.0$, were analyzed using SDS-plasminogen-gelatin gel under non-reducing conditions as described by Evans et al (15). The conditioned medium was concentrated 100 times, and the total amounts were used for analysis. The concentrated conditioned media and bound uPA were electrophoresed in a 10\% SDS-PAGE containing $1 \mathrm{mg} / \mathrm{ml}$ gelatin and $10 \mu \mathrm{g} / \mathrm{ml}$ plasminogen (Roche Diagnostic GmbH, Mannheim, Germany). After electrophoresis, the gel was washed twice with $2.5 \%$ Triton X-100 and incubated in reaction buffer containing $100 \mathrm{mM}$ Tris$\mathrm{HCl} \mathrm{pH} 7.8,0.15 \mathrm{M} \mathrm{NaCl}$, and $1 \%$ Triton $\mathrm{X}-100$ for $16-18 \mathrm{~h}$ at $37^{\circ} \mathrm{C}$, and then stained with Coomassie blue dye followed by a destaining step. The clear band at the molecular weight of approximately $40 \mathrm{kDa}$ represented urokinase plasminogen activator. Plasminogen-free gel was used as a negative control to confirm that the activity in plasminogen gelatin gel required the presence of plasminogen.

Quantification of total and phosphorylated forms of ERK1/2 and myosin regulatory light chain (MRLC). The levels of total and phosphorylated forms of ERK1/2 and MRLC were analyzed by immunoblotting using antibodies specific to total and phosphorylated forms of ERK1/2 and MRLC, respectively. Cells treated with various conditions were lysed with lysis buffer containing $0.1 \%$ SDS, $1 \%$ sodium deoxycholate, $1 \%$ Nonidet P-40, 1X protease inhibitor cocktail (Roche Diagnostics $\mathrm{GmbH}$ ), $2 \mathrm{mM}$ sodium orthovanadate, $40 \mathrm{mM}$ ß-glycerophosphate and $50 \mathrm{mM}$ sodium fluoride. The lysates were centrifuged at $12,000 \mathrm{x} \mathrm{g}$ for $10 \mathrm{~min}$ and then proteins were electrophoresed on $8 \%$ SDS-PAGE for analysis of ERK1/2 and 15\% SDS-PAGE for analysis of MRLC. After electroblotting, the nitrocellulose membranes were incubated with primary antibodies specific to ERK1/2 and phosphoERK1/2 (Cell Signaling Technology Inc.) and to MRLC (Sigma-Aldrich Corp.) and phospho-MRLC (Thr18/Ser19) (Santa Cruz Biotechnology, Inc., CA). The protein bands were visualized using an ECL kit (Pierce Biotechnology, Inc., Rockford, IL).

\section{Results}

Effects of PD98059 on in vitro invasion, migration and survival of MLL cell lines. We have previously shown that ERK $1 / 2$ is essential for the invasiveness of Dunning cells (10). Here, we further investigated how ERK1/2 regulates cell invasion by studying the effects of a MEK1 inhibitor, PD98059, on cell migration and adhesion, which are crucial events that occur during cell invasion. MLL cell invasiveness and migration were assayed using the in vitro Transwell method. Fig. 1 shows that treatment with PD98059 resulted in a dose-dependent reduction of cell migration with an inhibition profile similar to that of cell invasiveness. Moreover, the $\mathrm{IC}_{50}$ values of cell migration $(8.9 \pm 1.3 \mu \mathrm{M})$ and invasiveness $(7.7 \pm 1.0 \mu \mathrm{M})$ were not significantly different. Both cell invasiveness and motility were almost completely inhibited by $100 \mu \mathrm{M}$ PD98059.

To ensure that the migration inhibitory effect was not the result of PD98059 toxicity, the effect of the drug on cell survival was determined using the same conditions for the migration assay. Fig. 1 shows that 0-50 $\mu \mathrm{M}$ PD98059 did not have a significant effect on cell survival. At $100 \mu \mathrm{M}$ where migration and invasion were almost completely blocked, cell survival was inhibited by $<10 \%$.

Effect of PD98059 on adhesion of MLL cells to extracellular matrix. Given that MLL cells acquire great ability to adhere to the ECM component compared to their parental, low metastatic cells, and adhesion to ECM is a critical requirement for cell migration, we determined whether ERK activation was important for cell adhesion. Cells were treated with various concentrations of PD98059 and then allowed to adhere to Matrigel for $1 \mathrm{~h}$. Surprisingly, PD98059 treatment had no effect on MLL cell adhesion to the artificial extracellular matrix, Matrigel, at doses where migration and invasion of MLL cells were drastically inhibited (Fig. 2).

Effects of PD98059 on levels of secreted MMP and uPA. Besides migration and adhesion, extracellular matrix degradation is another key factor required for cell invasiveness. Many types of cancer cells secrete a large amount of matrixdegrading enzymes. The MLL cells overexpress MMP-2 and uPA, correlating with its enhanced metastatic ability (9). We determined the levels of MMP-2 and uPA secreted in the conditioned medium and uPA bound on the cell surface using gelatin (for MMP-2) and plasminogen-gelatin zymography (for uPA). Although PD98059 slightly reduced secreted MMP-2 levels in some experiments (Fig. 3), this inhibitory effect was neither dose-dependent nor statistically significant. 


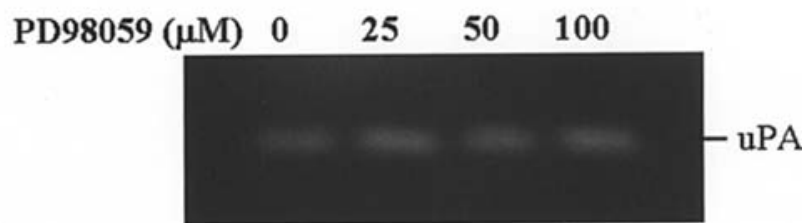

b

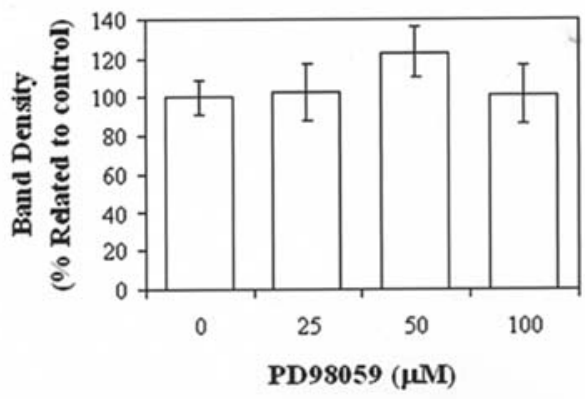

c

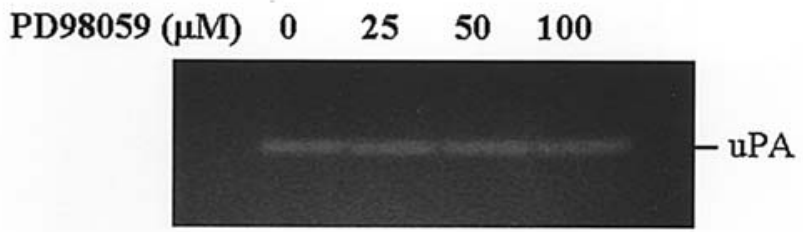

d

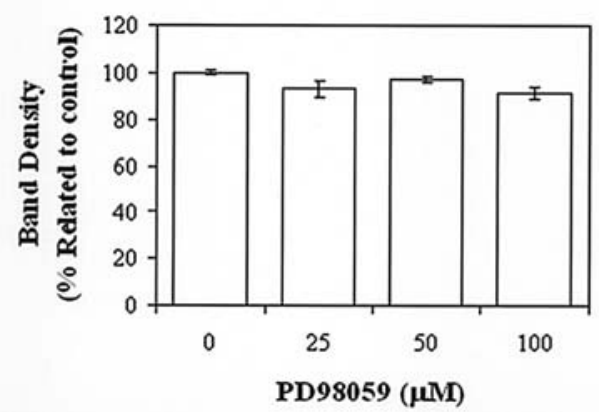

Figure 4 Plasminogen-gelatin zymography showing the effects of MEK1 inhibitor on the amount of soluble uPA secreted in the conditioned medium (a and b) and cell surface-bound uPA (c and d). Cells were treated with PD98059 in serum-free media for $6 \mathrm{~h}$. Then, the total concentrated conditioned media containing soluble uPA (a) and glycine-eluted cell surface-bound uPA (c) were analyzed by plasminogen-gelatin zymography. The clear band represents the plasminogen activator activity of uPA. The relative band densities of the soluble (b) and bound uPA (d) were quantitated using a gel densitometer. The data represent the mean \pm SEM of band density as a percentage related to the control from three independent experiments.

Fig. 4 shows that both soluble and bound uPA were marginally, if at all, affected by PD98059.

To show that the lack of change in MMP-2 and uPA activities was not due to the inability of PD98059 to execute inhibitory effects, we showed that phospho-ERK1/2 was drastically reduced in a dose-dependent manner (Fig. 5A). Furthermore, ERK1/2 phosphorylation was suppressed after the first 15 min of treatment with PD98059 and continued to be suppressed throughout the assay period (6 h) (Fig. 5B).
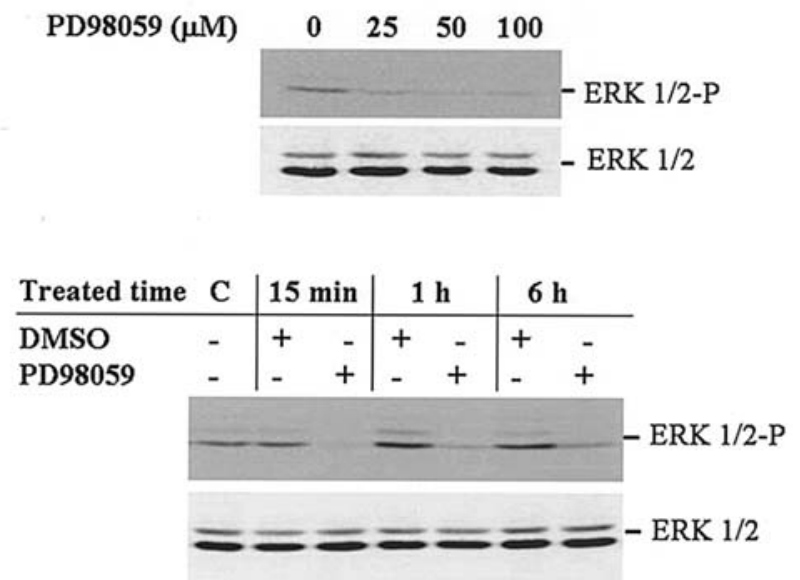

Figure 5. Effect of PD98059 on ERK phosphorylation. (a) Cells were treated with PD98059 in serum-free medium for $6 \mathrm{~h}$ and then cell lysates were analyzed for total and phospho-ERK1/2 by immunoblotting with anti-ERK1/2 and phospho-ERK1/2. (b). Cells were treated under the same conditions and harvested and lysed at various time points before assaying for total and phospho-ERK1/2. The results are representative of three independent experiments.

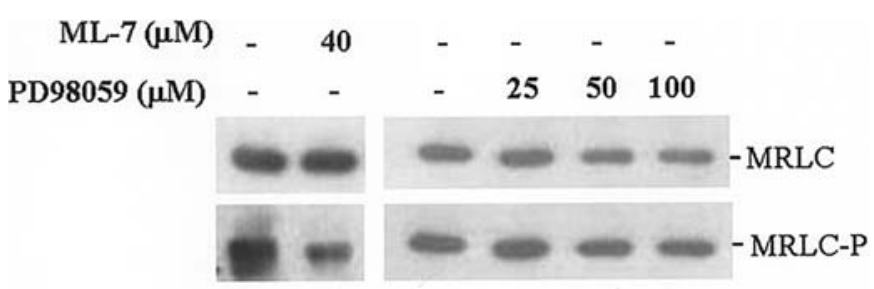

Figure 6. Effects of MEK1 inhibitor on levels of total and phospho-MRLC. Cells were treated with PD98059 or ML-7 for $6 \mathrm{~h}$ and then cell lysates were analyzed for total and phospho-MRLC by immunoblotting with antibodies specific to MRLC and phospho-MRLC. The results are representative of three independent experiments.

These results suggest that downstream effectors of phosphoERK1/2 should have been affected under this assay condition.

Effect of PD98059 on myosin regulatory light chain phosphorylation. The data shown above indicated that ERK1/2 activation is critical for cell migration. To investigate if the regulation of cell migration by ERK1/2 occurs through phosphorylation of MRLC, we determined the levels of MRLC phosphorylation upon treatment with PD98059 by immunoblotting. Treatment with up to $100 \mu \mathrm{M}$ PD98059 had no significant effect on the levels of phospho-MRLC, although this concentration had earlier been shown to suppress in vitro invasion of MLL cells by $>95 \%$ (Fig. 1). On the contrary, cells treated with ML-7, a MLCK inhibitor, showed an approximate $25 \%$ reduction of MRLC phosphorylation after normalizing with total MRLC (Fig. 6).

\section{Discussion}

There is a large amount of evidence demonstrating the role of ERK in invasiveness in many cancers, including prostate cancer (2). Our previous study showed that ERK $1 / 2$ is 
necessary for cell invasion of several cell lines in the Dunning rat prostatic adenocarcinoma family, and the steady-state levels of phosphorylated or activated ERK1/2 correlate with their metastatic and invasive abilities (10). When compared to the low metastatic progenitor cells, MLL cells with a high active ERK level exhibit enhancement of metastatic potential as well as other key characteristics of metastatic cells, namely enhanced cell adhesion, cell motility, and secretion of extracellular matrix degrading enzymes $(8,9)$. This suggests that ERK activation, at least in part, underlies the development of these metastatic phenotypes in MLL cells. To investigate if this was the case, we inhibited MEK1, an upstream regulator of ERK1/2, with PD98059 and observed the biological effects of treated cells. The results showed that PD98059, a specific MEK1 inhibitor, suppressed the cell motility and invasion of MLL cells with similar inhibition profiles and $\mathrm{IC}_{50}$ values but had no effect on MRLC phosphorylation, attachment to Matrigel or the levels of secreted MMP-2 and uPA.

These data indicate that ERK activation promotes cancer cell invasiveness by enhancing its ability to move. Consistent with our data, ERK1/2 has been shown to play an important role in regulating cell migration in numerous cell types (16). Inhibition of the ERK pathway by MEK1 inhibitor, PD98059 or U0126, or by dominant negative ERK suppresses cell motility in diverse cell types in response to extracellular matrix components, growth factors and uPA $(6,17)$, while constitutively active MEK1 promotes cell migration (5).

MEK1 promotes cell migration by phosphorylating MLCK, which leads to the phosphorylation of myosin regulatory light chain and enhanced cell motility in COS (5) and MCF-7 cells (18). Previous data from our laboratory have demonstrated that MLCK is also critical for the invasiveness and motility of MLL cells (14), suggesting that inhibition of ERK1/2 may also result in the reduction of MLCK phosphorylation, thereby inhibiting cell motility and invasion. However, our present results showed no change in MRLC phosphorylation after PD98059 treatment, suggesting that MLCK may not be a major substrate of ERK1/2 in MLL cells. Other ERK substrates likely to participate in cell migration are focal adhesion kinase (FAK), paxillin, and calpain (16). Phosphorylation of paxillin by ERK promotes paxillin-FAK association and FAK phosphorylation and activation, which regulates focal adhesion turnover and PI3K-Rac mediated lamellipodia protrusion (19-21). M-calpain is also phosphorylated and activated by ERK. This active M-calpain then degrades FAK and cytoskeletal proteins to promote focal adhesion disassembly (22). These proteins may also play roles in the ERK-induced motility of MLL cells.

Motile cells need to attach to the extracellular matrix in order to migrate. Thus, cell adhesion constitutes one of the critical properties required for cell migration. The fact that the highly metastatic motile MLL cell shows greater ability than its parental cell to attach to the extracellular matrix protein, fibronectin (8), and that the chemotherapeutic drug, pentosan, which alters cell-extracellular matrix interaction, inhibits cell motility and prolongs the survival of rats injected with MLL cells (23), confirm the association between the adhesion of cells to the extracellular matrix and motility of this cell line. However, our results showed that the number of cells attached to Matrigel within $1 \mathrm{~h}$ was not altered after treatment with PD98059, although the drug drastically inhibited motility. This is consistent with previous studies reporting that MEK1 inhibition does not affect cell adhesion but inhibits motility $(5,18)$. Although ERK has been shown to associate with adhesion molecules such as integrin (24), this usually occurs after the cells have been treated with an inhibitor for $48 \mathrm{~h}$ (25). In addition to integrin, ERK has also been implicated in focal adhesion molecules such as FAK and paxillin; however, these molecules are believed to play a role in focal adhesion turnover, which is important for cell motility rather than cell adhesion.

Breakdown of the extracellular matrix barrier is also a fundamental step for cancer invasion. To overcome this barrier, invasive cancer cells produce proteases such as MMPs and uPA to degrade this barrier. Up-regulation of these proteases is associated with tumor progression and metastasis in many cancers including prostate cancer $(26,27)$. In MLL cells, two matrix-degrading enzymes, MMP-2 and uPA, have been shown to be overexpressed and important for extracellular matrix degradation (9), invasion and metastasis $(15,28,29)$. The role of ERK1/2 in regulating MMP-2 expression varies. ERK1/2 induces MMP-2 expression in pancreatic (30) and prostate cancer cell lines (31) but plays no role in induction of MMP-2 in MCF10A (32) and MeWo melanoma cells (33) and even negatively regulates MMP-2 expression in the Lewis lung carcinoma cell line (34). ERK1/2 has also been shown to induce uPA expression in diverse cancer cells such as squamous cell carcinoma (35), ovarian cancer (7), and pancreatic cancer cell lines (30). However, ERK1/2 appears to have a minimal role in inducing MMP-2 and uPA activity in the MLL cells under our assay conditions. The lack of change in MMP-2 and uPA activities was not likely caused by the incapability of PD98059 to suppress ERK1/2 phosphorylation and subsequent expression of these genes, as we have shown that phospho-ERK1/2 was drastically reduced under this assay condition. Therefore, it may be extrapolated that the downstream effectors of ERK1/2 were suppressed. It is thus likely that the MMP-2 and UPA regulation of MLL cells is independent of the MEK1/ERK pathway. Supporting this argument is a report by $\mathrm{Li}$ et al, demonstrating that LPS-induced uPA expression involves the Ras/Raf1/NF-кB pathway, independent of MEK1/ERK (36).

In summary, we have shown that the impairment of invasion of the MLL cell line by PD98059, an inhibitor of MEK1, was mainly attributed to the inhibition of cell motility rather than the suppression of cell adhesion or extracellular matrix degradation. These findings suggest that the upregulation of active ERK acquired in the highly metastatic MLL cell line results in the enhancement of cell motility and invasion but not other phenomena associated with metastasis. Although ERK regulates MLL cell invasion and migration, this process is unlikely to involve MLCK. The mechanisms of ERK-induced migration in the MLL cell line remain to be elucidated and would help provide a better molecular understanding of the role of ERK1/2 in the development of metastasis.

\section{Acknowledgements}

This work was supported by grants from Mahidol University, Thailand and the Thailand Research Fund. We thank Dr. K 
Pienta for providing the MLL cell line and Professor P. Wilairat for the critical reading of this manuscript.

\section{References}

1. Liotta LA and Stetler-Stevenson WG: Tumor invasion and metastasis: an imbalance of positive and negative regulation. Cancer Res 51: 5054s-5059s, 1991.

2. Reddy KB, Nabha SM and Atanaskova N: Role of MAP kinase in tumor progression and invasion. Cancer Metastasis Rev 22: 395-403, 2003.

3. Gioeli D, Mandell JW, Petroni GR, Frierson HF Jr and Weber MJ: Activation of mitogen-activated protein kinase associated with prostate cancer progression. Cancer Res 59: 279-284, 1999.

4. Adeyinka A, Nui Y, Cherlet T, Snell L, Watson PH and Murphy LC: Activated mitogen-activated protein kinase expression during human breast tumorigenesis and breast cancer progression. Clin Cancer Res 8: 1747-1753, 2002.

5. Klemke RL, Cai S, Giannini AL, Gallagher PJ, de Lanerolle P and Cheresh DA: Regulation of cell motility by mitogen-activated protein kinase. J Cell Biol 137: 481-492, 1997.

6. Nguyen DH, Hussaini IM and Gonias SL: Binding of urokinasetype plasminogen activator to its receptor in MCF-7 cells activates extracellular signal-regulated kinase 1 and 2 which is required for increased cellular motility. J Biol Chem 273: 8502-8507, 1998

7. Ahmed N, Pansino F, Baker M, Rice G and Quinn M: Association between alphavbeta6 integrin expression, elevated p42/44 kDa MAPK, and plasminogen-dependent matrix degradation in ovarian cancer. J Cell Biochem 84: 675-686, 2002.

8. Cooper CR, Donald C, Emmett N, Harris-Hooker S and Cooke DB III: Adhesion and invasion potential of rat prostatic cancer cells: correlation with metastatic potential. Invasion Metastasis 13: 178-184, 1993.

9. Quax PH, de Bart AC, Schalken JA and Verheijen JH: Plasminogen activator and matrix metalloproteinase production and extracellular matrix degradation by rat prostate cancer cells in vitro: correlation with metastatic behavior in vivo. Prostate 32: 196-204, 1997.

10. Suthiphongchai T, Promyart P, Virochrut S, Tohtong R and Wilairat P: Involvement of ERK1/2 in invasiveness and metastatic development of rat prostatic adenocarcinoma. Oncol Res 13: 253-259, 2003.

11. Isaacs JT, Isaacs WB, Feitz WF and Scheres J: Establishment and characterization of seven Dunning rat prostatic cancer cell lines and their use in developing methods for predicting metastatic abilities of prostatic cancers. Prostate 9: 261-281, 1986.

12. Albini A, Iwamoto $\mathrm{Y}$, Kleinman $\mathrm{HK}$, et al: A rapid in vitro assay for quantitating the invasive potential of tumor cells. Cancer Res 47: 3239-3245, 1987.

13. Denizot F and Lang R: Rapid colorimetric assay for cell growth and survival. Modifications to the tetrazolium dye procedure giving improved sensitivity and reliability. J Immunol Methods 89: 271-277, 1986.

14. Tohtong R, Phattarasakul K, Jiraviriyakul A and Sutthiphongchai T: Dependence of metastatic cancer cell invasion on MLCK-catalyzed phosphorylation of myosin regulatory light chain. Prostate Cancer Prostatic Dis 6: 212-216, 2003.

15. Evans CP, Elfman F, Parangi S, Conn M, Cunha G and Shuman MA: Inhibition of prostate cancer neovascularization and growth by urokinase-plasminogen activator receptor blockade. Cancer Res 57: 3594-3599, 1997.

16. Huang C, Jacobson K and Schaller MD: MAP kinases and cell migration. J Cell Sci 117: 4619-4628, 2004.

17. Cheresh DA, Leng J and Klemke RL: Regulation of cell contraction and membrane ruffling by distinct signals in migratory cells. J Cell Biol 146: 1107-1116, 1999.

18. Nguyen DH, Catling AD, Webb DJ, et al: Myosin light chain kinase functions downstream of Ras/ERK to promote migration of urokinase-type plasminogen activator-stimulated cells in an integrin-selective manner. J Cell Biol 146: 149-164, 1999.
19. Liu ZX, Yu CF, Nickel C, Thomas S and Cantley LG: Hepatocyte growth factor induces ERK-dependent paxillin phosphorylation and regulates paxillin-focal adhesion kinase association. J Biol Chem 277: 10452-10458, 2002.

20. Ishibe S, Joly D, Liu ZX and Cantley LG: Paxillin serves as an ERK-regulated scaffold for coordinating FAK and Rac activation in epithelial morphogenesis. Mol Cell 16: 257-267, 2004.

21. Webb DJ, Donais K, Whitmore LA, et al: FAK-Src signalling through paxillin, ERK and MLCK regulates adhesion disassembly. Nat Cell Biol 6: 154-161, 2004.

22. Cuevas BD, Abell AN, Witowsky JA, et al: MEKK1 regulates calpain-dependent proteolysis of focal adhesion proteins for rear-end detachment of migrating fibroblasts. EMBO J 22: 3346-3355, 2003.

23. Pienta KJ, Murphy BC, Isaacs WB, Isaacs JT and Coffey DS: Effect of pentosan, a novel cancer chemotherapeutic agent, on prostate cancer cell growth and motility. Prostate 20: 233-241, 1992.

24. Sawhney RS, Sharma B, Humphrey LE and Brattain MG: Integrin alpha2 and extracellular signal-regulated kinase are functionally linked in highly malignant autocrine transforming growth factor-alpha-driven colon cancer cells. J Biol Chem 278: 19861-19869, 2003

25. Woods D, Cherwinski H, Venetsanakos E, et al: Induction of beta3-integrin gene expression by sustained activation of the Ras-regulated Raf-MEK-extracellular signal-regulated kinase signaling pathway. Mol Cell Biol 21: 3192-3205, 2001.

26. Bjorklund $\mathrm{M}$ and Koivunen E: Gelatinase-mediated migration and invasion of cancer cells. Biochim Biophys Acta 1755: 37-69, 2005.

27. Sidenius N and Blasi F: The urokinase plasminogen activator system in cancer: recent advances and implication for prognosis and therapy. Cancer Metastasis Rev 22: 205-222, 2003.

28. Lokeshwar BL: MMP inhibition in prostate cancer. Ann NY Acad Sci 878: 271-289, 1999.

29. Rabbani SA and Gladu J: Urokinase receptor antibody can reduce tumor volume and detect the presence of occult tumor metastases in vivo. Cancer Res 62: 2390-2397, 2002.

30. Lee KH, Hyun MS and Kim JR: Growth factor-dependent activation of the MAPK pathway in human pancreatic cancer: MEK/ERK and p38 MAP kinase interaction in uPA synthesis. Clin Exp Metastasis 20: 499-505, 2003.

31. Vayalil PK and Katiyar SK: Treatment of epigallocatechin-3gallate inhibits matrix metalloproteinases- 2 and -9 via inhibition of activation of mitogen-activated protein kinases, c-jun and NF-kappaB in human prostate carcinoma DU-145 cells. Prostate 59: 33-42, 2004.

32. Kim ES, Kim MS and Moon A: TGF-beta-induced upregulation of MMP-2 and MMP-9 depends on p38 MAPK, but not ERK signaling in MCF10A human breast epithelial cells. Int J Oncol 25: 1375-1382, 2004.

33. Denkert C, Siegert A, Leclere A, Turzynski A and Hauptmann S: An inhibitor of stress-activated MAP-kinases reduces invasion and MMP-2 expression of malignant melanoma cells. Clin Exp Metastasis 19: 79-85, 2002.

34. Zhang D, Bar-Eli M, Meloche S and Brodt P: Dual regulation of MMP-2 expression by the type 1 insulin-like growth factor receptor: the phosphatidylinositol 3-kinase/Akt and Raf/ERK pathways transmit opposing signals. J Biol Chem 279: 1968319690, 2004.

35. Simon C, Juarez J, Nicolson GL and Boyd D: Effect of PD 098059, a specific inhibitor of mitogen-activated protein kinase kinase, on urokinase expression and in vitro invasion. Cancer Res 56: 5369-5374, 1996.

36. Li H, Ye X, Mahanivong C, Bian D, Chun J and Huang S: Signaling mechanisms responsible for lysophosphatidic acidinduced urokinase plasminogen activator expression in ovarian cancer cells. J Biol Chem 280: 10564-10571, 2005. 